\title{
A Semana Santa de Braga: Impacto Económico, Perfil do Visitante e Satisfação
}

https://doi.org/10.21814/uminho.ed.48.13

\section{João Cerejeira}

Núcleo de Investigação em Políticas Económicas e Empresariais, Escola de Economia e Gestão, Universidade do Minho, Braga, Portugal https://orcid.org/0000-0001-6544-6116

joao.cerejeira@eeg.uminho.pt

Isabel Correia

JusGov, Escola de Direito, Universidade do Minho, Braga, Portugal https://orcid.org/0000-0002-6735-3148

icorreia@eeg.uminho.pt

Sílvia Sousa

Núcleo de Investigação em Políticas Económicas e Empresariais, Escola de Economia e Gestão, Universidade do Minho, Braga, Portugal https://orcid.org/0000-0002-1148-0754 ssousa@eeg.uminho.pt

\section{Resumo}

A Semana Santa de Braga constitui, não apenas um fenómeno religioso, mas, sobretudo, um evento cultural que atrai, ano após ano, um número significativo de turistas. Motivado pelo impacto económico estimado para o ano de 2017, que traduz a inegável relevância deste evento para a economia da cidade e da região, o presente estudo pretende caracterizar o perfil do visitante para assim contribuir para a oferta de programações adequadas e a implementação de estratégias eficazes de marketing turístico. A abordagem baseia-se na perspetiva do consumidor, procurando determinar quem viaja para assistir ao evento, as suas motivações e o seu grau de satisfação relativamente a este evento. A metodologia utilizada usa dados primários e inclui a estimação de modelos econométricos que permitem identificar o perfil do visitante e distinguir entre visitantes nacionais e estrangeiros, bem como aferir o seu grau de satisfação, comparando-a com a revelada pelos residentes. Os resultados obtidos sugerem perfis de visitantes diferentes, com base na sua origem geográfica, sugerindo a necessidade de moldar a oferta e a sua promoção, de acordo com o perfil de visitante pretendido. Contudo, diferentes origens não se refletem, em geral, no nível de 
satisfação do visitante, estando esta última relacionada com outras características sociodemográficas.

\section{Palavras-chave}

turismo, perfil do visitante, satisfação, impacto económico, Semana Santa

\section{Introdução}

Dada a sua importância para as economias locais, o turismo tornou-se um tópico de interesse crescente na literatura económica. A avaliação do impacto económico de eventos de interesse turístico tem vindo a merecer a atenção de um relativamente vasto campo dessa literatura, permanecendo em aberto a questão de saber se essas experiências turísticas são um constructo unidimensional ou multidimensional (Sánchez-Cañizares \& López-Guzmán, 2012). Um destino turístico (por exemplo, cidade, região ou local) é cada vez menos visto como um conjunto de recursos naturais, culturais, artísticos ou ambientais distintos, para ser considerado uma carteira complexa e integrada de serviços oferecidos por um destino que fornece experiências ajustadas às necessidades dos turistas (Cracolici \& Nijkamp, 2009).

A Semana Santa de Braga, a mais antiga e maior de Portugal, constitui, não apenas um fenómeno religioso, mas, sobretudo, um evento cultural. Os eventos culturais/religiosos servem de motivo para a atração turística, criando emprego e promovendo o desenvolvimento local. Com base neste pressuposto, uma vasta literatura económica tem versado sobre os efeitos económicos da cultura em termos da criação de emprego e da sua contribuição para o produto interno bruto (PIB) da região.

Tipicamente, a avaliação dos impactos económicos de eventos culturais/religiosos centra-se nos benefícios económicos associados ao turismo. Na determinação do impacto direto da Semana Santa de Braga, de 2017, Cerejeira et al. (2018) estimaram que, durante esse período, cerca de 64.000 pessoas tenham visitado a cidade e, destas, cerca de 22.000 tenham pernoitado na cidade. Estimaram ainda que cada visitante tenha realizado uma despesa média diária entre os $47,3 €$ e os $120,9 €$, dependendo da sua origem e do tipo de alojamento utilizado, o que perfaz um total de despesa de cerca de 5.000.000€. Considerando apenas a despesa adicional associada ao evento, estimaram um impacto direto que ultrapassa os $2.900 .000 €$.

Além do impacto direto da Semana Santa, há ainda que considerar os seus impactos indiretos e induzidos. Ou seja, esta procura de bens e serviços pelos visitantes vai ter um impacto indireto sobre os fornecedores dos estabelecimentos que vendem esses bens e serviços e o aumento da produção local de bens e serviços para satisfazer as necessidades dos visitantes vai ter efeitos no rendimento (salários e rendimento de capital) e no emprego da região, provocando acréscimos no consumo que levarão, consequentemente, a acréscimos na produção - os efeitos induzidos. 
Aplicando os multiplicadores disponíveis para a economia portuguesa, Cerejeira et al. (2018) apuraram um impacto total (direto, indireto e induzido) no volume de negócios na ordem dos $12.900 .000 €$, que tem associado um valor acrescentado de cerca de 7.300.000€. Os impactos direto, indireto e induzido no volume de negócios rondam os $7.500 .000 €$ e os $4.200 .000 €$ no valor acrescentado.

Dada a importância deste evento para a economia da cidade e da região, caracterizar o perfil dos visitantes e a sua satisfação contribui para a compreensão do seu comportamento e logo permite adequar a oferta de programações e implementar estratégias eficazes de marketing turístico. Assim, o objetivo deste trabalho é identificar e caracterizar o perfil do visitante que se desloca a Braga, durante as festividades da Semana Santa, considerando alguns dos fatores que potencialmente determinam a escolha do destino, tais como a idade, o género, o rendimento, a origem, a motivação da visita e os gastos (efetuados ou previstos) do visitante. Analisam-se ainda as perceções dos visitantes acerca da qualidade da programação do evento, dos serviços utilizados e da área visitada, por forma a determinar o seu grau de satisfação. A origem geográfica dos visitantes é particularmente analisada, comparando-se os perfis dos visitantes nacionais e estrangeiros. A origem dos visitantes é ainda tida em conta na análise da sua satisfação, esta última comparada com a revelada pelos residentes.

O presente estudo começa por apresentar, de forma sucinta, o contexto socioecónomico de Braga e a Semana Santa de Braga. Segue-se um breve enquadramento teórico onde se apresentam, designadamente, alguns estudos sobre o perfil do turista/visitante e a evidência empírica reportada acerca do impacto das características sociodemográficas no seu grau de satisfação. Após a descrição da metodologia adotada, assim como dos dados e suas fontes, segue-se a apresentação dos resultados e sua discussão e análise. 0 estudo conclui com um conjunto de breves reflexões sobre a relevância dos resultados obtidos para a definição de medidas de política ou estratégias de marketing turístico.

\section{A Semana Santa de Braga}

Braga é uma cidade localizada no norte de Portugal. Com mais de 2.000 anos de uma história riquíssima, Braga é também considerada uma das mais jovens cidades europeias. Em termos económicos, e seguindo a tendência nacional, Braga apresentou, entre 2009 e 2015, uma evolução positiva dos indicadores relativos ao turismo. Destacam-se o aumento do número de empresas de alojamento (+62\%) e restauração (+19\%), do número de estabelecimentos hoteleiros (+42\%) e consequente capacidade hoteleira ( $+43 \%$ no número de camas), a que se associa um aumento do número de hóspedes ( $+53 \%$ de dormidas), com uma crescente proporção de hóspedes estrangeiros, de 37\% em 2010 para 42\% em 2015, segundo o Instituto Nacional de Estatística.

A Semana Santa de Braga é a mais antiga e maior de Portugal, tendo sido o primeiro evento de natureza religiosa a ser declarado de "interesse para o Turismo", em fevereiro de 2012, pelo Turismo de Portugal. Estando associada às representações 
comemorativas da paixão e morte de Jesus, a Semana Santa de Braga, dando continuidade à sua tradição histórica, apresenta-se hoje enriquecida com elementos inovadores e exclusivos, integrando no seu programa geral de atos religiosos e atos culturais, entre os quais procissões, concertos e exposições. Esta combinação de celebrações de natureza religiosa e cultural, associada a um relevante património histórico, conduz à identificação da Semana Santa de Braga como um importante ativo cultural e religioso, que se tem vindo a revelar na crescente diversidade de eventos incluídos na programação da Semana Santa de Braga.

Enquadrando-se no âmbito do turismo cultural e religioso, o impacto económico e social da Semana Santa de Braga, à semelhança do que se observa relativamente a outras celebrações da mesma natureza em outros pontos do globo, tem vindo a suscitar um crescente interesse por parte dos investigadores. Santos (2011) e Silva (2015), por exemplo, concluem sobre a importância da dinamização económica potenciadora do desenvolvimento da cidade, entre os principais benefícios do evento apontados pelos inquiridos, sinalizando a circulação automóvel e estacionamento como os principais aspetos a melhorar. A estes contributos para a riqueza e emprego da cidade e da região, Barroso (2018) acrescenta a importância deste evento para a valorização do património e a afirmação de Braga como destino turístico.

\section{Perfil do Visitante, Satisfação e Lealdade}

A relação entre o perfil do turista/visitante e a satisfação é particularmente relevante, dada a importância das perceções dos turistas na escolha do destino, no consumo de bens e serviços durante a estadia e na decisão de retornar.

A satisfação dos turistas e/ou visitantes é um dos aspetos mais explorados neste contexto, sendo um fator a ter em consideração para aumentar a competitividade do destino e um conceito central para compreender o seu comportamento durante a estadia e no futuro (Andriotis et al., 2008).

Os estudos de satisfação geralmente incluem avaliações de diferentes atributos do destino numa escala ordinal. Através dessa escala, o turista pode expressar a sua satisfação, insatisfação ou indiferença relativamente a cada atributo. A satisfação pode ser determinada por fatores objetivos (por exemplo, as características dos produtos e serviços) ou subjetivos (por exemplo, as necessidades dos clientes e as emoções) e está fortemente relacionada com o conceito de lealdade para com o destino, designadamente com a decisão de repetir ou recomendar a visita (Correia et al., 2017).

Vários estudos têm procurado estabelecer a relação entre a satisfação e as características demográficas e comportamentais dos turistas, mas, em geral, a literatura mostra que não há consenso sobre o papel desses fatores na determinação da satisfação (ver, por exemplo, Agyeiwaah et al., 2016; Alegre \& Garau, 2010; Valle et al., 2006).

Ainda que o consenso não esteja estabelecido relativamente ao tipo de impacto, há evidência de que as características dos indivíduos influenciam a sua satisfação (por 
exemplo, Kerstetter et al., 2001, ou Master \& Prideaux, 2000), designadamente: o género (Huh, 2002; Qu \& Li, 1997); o seu nível de rendimento (Esu \& Arrey, 2009), particularmente no que diz respeito ao alojamento, sendo menos relevante no que diz respeito a atrações, eventualmente por algumas serem gratuitas ou monetariamente acessíveis (Agyeiwaah et al., 2016); o nível de escolaridade, com indivíduos com níveis mais elevados a apresentar um nível de exigência superior (Qu \& Li, 1997; Valle et al., 2006) ou com resultados ambíguos (Mechinda et al., 2009); ou a origem dos indivíduos, com os nacionais a apresentarem níveis de satisfação inferiores, decorrentes da perceção de que são menos bem tratados do que os estrangeiros (Valle et al., 2006).

\section{Metodologia e Dados}

No sentido de dar resposta ao objetivo de traçar o perfil do turista e do visitante de Braga durante a Semana Santa e avaliar a satisfação destes com este evento e com a cidade de Braga, foi aplicado um questionário composto por 20 questões. Com base neste questionário foram obtidos detalhes básicos sobre os visitantes/turistas (cinco questões) e a sua estadia em Braga (11 questões).

Duas questões baseadas numa escala de Likert com 5 níveis (de 1 - muito fraco a 5 muito bom) foram estruturadas para medir os níveis de satisfação dos turistas com a programação da Semana Santa e com um conjunto de atributos da cidade de Braga. A opção "sem opinião" foi também incluída como possibilidade de resposta, para o caso dos respondentes que não tinham tido, até ao momento da entrevista, qualquer experiência relativamente a algum dos atributos da programação ou da cidade.

Os atributos avaliados, que representam os atributos do destino incluíam: o comércio, a restauração/gastronomia, o património cultural e arquitetónico, o espaço de circulação pedestre, a circulação automóvel e o estacionamento, a segurança, a limpeza em geral, a hospitalidade das pessoas e a relação preço/qualidade dos serviços prestados.

Relativamente à programação da Semana Santa, o questionário incluía a avaliação das procissões e das celebrações religiosas, dos concertos e espetáculos e das exposições. Incluía ainda a avaliação de um conjunto de atributos tais como a qualidade e a diversidade da programação, a sua divulgação e os locais escolhidos para acolher essa programação.

Os questionários foram aplicados aos transeuntes, entre os dias 12 de abril e 15 de abril de 2017, tendo sido obtidas 1.106 respostas. A margem de erro máxima associada a uma amostra aleatória de 1.106 inquiridos é de 2,95\%, com um nível de confiança de $95 \%$. Foram entrevistados aleatoriamente os transeuntes das ruas do centro histórico, tendo as entrevistas decorrido no período entre as $14 \mathrm{~h}$ e as $20 \mathrm{~h}$ na quarta-feira e na quinta-feira e entre as $11 \mathrm{~h}$ e as $21 \mathrm{~h}$ na sexta-feira e no sábado, como se observa na Tabela 1. 


\section{Tabela 1}

Inquérito de rua:

calendarização e

número de respostas.

$\begin{array}{lcc}\text { Dia } & \text { Horário } & \text { Respostas } \\ \text { Quarta } & 14 \mathrm{~h}-20 \mathrm{~h} & 216 \\ \text { Quinta } & 14 \mathrm{~h}-20 \mathrm{~h} & 207 \\ \text { Sexta } & 11 \mathrm{~h}-21 \mathrm{~h} & 424 \\ \text { Sábado } & 11 \mathrm{~h}-21 \mathrm{~h} & 259 \\ \text { Total } & & 1.106\end{array}$

A análise econométrica do perfil do visitante estrangeiro, por comparação com o visitante nacional, envolveu a estimação de um modelo Probit, sendo este um modelo que permite a predição de valores tomados por uma variável categórica binária, a partir de uma série de variáveis explicativas contínuas e/ou binárias.

Analisamos também a associação entre um conjunto de atributos sociodemográficos dos visitantes e a sua satisfação com diferentes aspetos da programação e com a Semana Santa de Braga em geral. Para tal, estimaram-se outros sete modelos Probit, com o objetivo de estimar os determinantes sociodemográficos da satisfação dos inquiridos relativamente a seis dimensões relacionadas com a programação e o evento (procissões; exposições; programa; diversidade; divulgação e locais) e a satisfação com a Semana Santa de Braga em termos globais.

\section{Resultados}

Com base nas respostas obtidas aos questionários, é possível antecipar o perfil do visitante, tendo em conta um conjunto de caraterísticas socioeconómicas, distinguindo entre visitantes nacionais e estrangeiros (Tabela 2).

\section{Tabela 2}

Caracterização da amostra.

$\begin{array}{lccc} & \text { Nacional } & \text { Estrangeiro } & \text { Total } \\ & \% & \% & \% \\ \text { Género } & & & \\ \text { Masculino } & 43,5 & 51,8 & 48,3 \\ \text { Feminino } & 56,5 & 48,2 & 51,7 \\ \text { Habilitações } & 21,5 & 5,0 & 12,0 \\ \text { Básico } & 22,4 & 22,3 & 22,3 \\ \text { Secundário } & 56,2 & 72,7 & 65,7 \\ \text { Superior } & & & 7,6 \\ \text { Escalão etário } & 9,4 & 6,3 & 22,5 \\ \text { [16-24] } & 26,9 & 38,5 & 45,5 \\ \text { [25-44] } & 44,7 & 46,2 & 13,3\end{array}$


Como se pode observar, no que diz respeito aos visitantes nacionais, há uma maior percentagem de mulheres, cerca de $56 \%$ possuem o ensino superior e cerca de $45 \%$ encontram-se na faixa etária dos 45 aos 64 anos, aumentando para cerca de $72 \%$, quando se considera a faixa etária dos 25 aos 64 anos. A análise dos dados relativamente aos visitantes estrangeiros sugere uma maior percentagem de homens, uma percentagem superior de indivíduos com o ensino superior (cerca de 73\%) e uma concentração semelhante dos visitantes entre os 45 e 64 anos (cerca de $46 \%$ ) e superior dos visitantes entre 25 e 64 anos (85\%).

Recorrendo a modelos econométricos de escolha discreta (Probit), estimamos a probabilidade de encontrarmos, entre os visitantes estrangeiros, determinadas características sociodemográficas, reportando-se, na Tabela 3, os efeitos marginais. Os resultados corroboram a análise descritiva, permitindo elaborá-la em termos quantitativos.

\begin{tabular}{|c|c|}
\hline Variáveis independentes & Efeitos marginais \\
\hline \multirow[t]{2}{*}{ Sexo feminino } & $-0,089^{* * *}$ \\
\hline & $(0,034)$ \\
\hline \multirow[t]{2}{*}{ Escalão etário [25-44] } & $0,179^{* * *}$ \\
\hline & $(0,069)$ \\
\hline \multirow[t]{2}{*}{ Escalão etário [45-64] } & $0,144^{* *}$ \\
\hline & $(0,067)$ \\
\hline \multirow[t]{2}{*}{ Escalão etário [65-...] } & 0,031 \\
\hline & $(0,081)$ \\
\hline \multirow[t]{2}{*}{ Habilitações ensino secundário } & $0,307^{* * *}$ \\
\hline & $(0,061)$ \\
\hline \multirow[t]{2}{*}{ Habilitações ensino superior } & $0,367^{* * *}$ \\
\hline & $(0,054)$ \\
\hline Observações & 775 \\
\hline
\end{tabular}

A análise dos resultados permite concluir que, em média, um visitante do sexo feminino tem uma probabilidade $9 \%$ inferior de ser estrangeiro; um visitante com idade entre os 25 e os 44 anos tem uma probabilidade $17,9 \%$ superior de ser estrangeiro e um visitante com idade entre os 45 e os 64 anos tem uma probabilidade 14,4\% superior de ser estrangeiro, comparada com a probabilidade de um visitante com idade até aos 24 anos; e um visitante com o ensino secundário tem uma probabilidade $30,7 \%$ superior de ser estrangeiro e um visitante com o ensino superior tem uma probabilidade $36,7 \%$ superior de ser estrangeiro, comparativamente a um visitante com o ensino básico. Resumindo, os visitantes do sexo masculino, mais velhos e com níveis de escolaridade mais elevados, têm maior probabilidade de ser estrangeiros.

A informação sobre o perfil do visitante ganha relevância quando relacionada com o seu grau de satisfação, permitindo sinalizar as características individuais que determinam a satisfação. Em geral, os resultados apontam para níveis de satisfação elevados relativamente aos elementos da programação, ainda que se observe uma proporção significativa de indivíduos sem opinião (Figura 1).

\section{Tabela 3}

Características dos visitantes estrangeiros, por comparação com os nacionais. Nota. Erros-padrão entre parêntesis. ${ }^{* *}$ $p<0,01,{ }^{* *} p<0,05$, ${ }^{*} p<0,1$. Categorias base: sexo masculino; escalão etário [16-24]; habilitações ensino básico. Variável dependente: Visitante estrangeiro $=1 \mid$ Nacional $=0$ 


\section{Figura 1}

Avaliação da programação.

\section{Tabela 4}

Determinantes da satisfação da programação - visitantes (modelos Probit).

Nota. Erros-padrão entre parêntesis. ${ }^{* *} p$ $<0,01,{ }^{* *} p<0,05,{ }^{*} p$ $<0,1$. Categorias base: sexo masculino; escalão etário [16-24]; habilitações ensino básico. Variável dependente $=$ 0 para respostas iguais ou inferiores a bom; $=1$ para respostas $=$ muito bom.

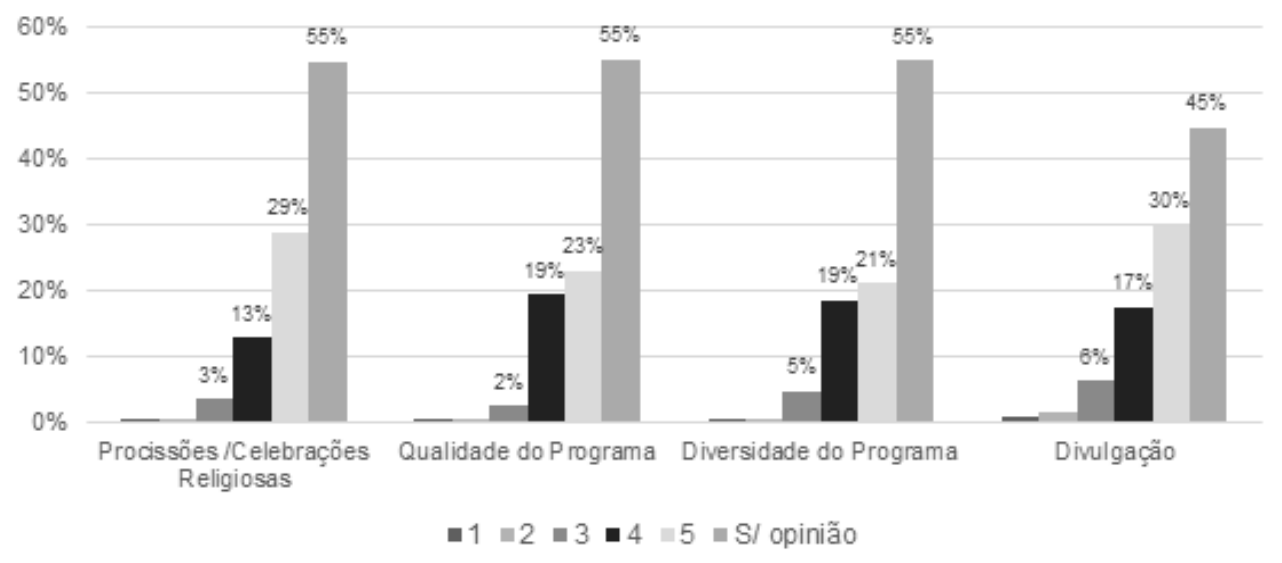

Uma possível razão para esta ausência de opinião poderá decorrer do facto de, aquando da resposta ao questionário, o indivíduo ainda não ter tido nenhuma experiência relacionada com a programação do evento (Cerejeira et al., 2018). Considerando as avaliações dos visitantes e distinguindo entre dois grupos, designadamente um grupo com avaliações muito bom e outro com avaliações iguais ou inferiores a bom, estimaram-se, separadamente, modelos Probit para um conjunto de dimensões, relacionadas com a programação e o evento: procissões; exposições; programa; diversidade; divulgação; locais e, finalmente, em termos globais, reportando-se os resultados na Tabela 4.

\begin{tabular}{|c|c|c|c|c|c|c|c|c|}
\hline Variáveis & $\begin{array}{l}\text { Procissões } \\
\text { (1) }\end{array}$ & $\begin{array}{c}\text { Concertos } \\
\text { (2) }\end{array}$ & $\begin{array}{c}\text { Exposições } \\
\text { (3) }\end{array}$ & $\begin{array}{c}\text { Programa } \\
\text { (4) }\end{array}$ & $\begin{array}{c}\text { Diversidade } \\
\text { (5) }\end{array}$ & $\begin{array}{c}\text { Divulgação } \\
\text { (6) }\end{array}$ & $\begin{array}{c}\text { Locais } \\
\text { (7) }\end{array}$ & $\begin{array}{c}\text { Global } \\
\text { (8) }\end{array}$ \\
\hline $\begin{array}{l}\text { Visitante es- } \\
\text { trangeiro }\end{array}$ & $\begin{array}{c}0,008 \\
(0,062)\end{array}$ & $\begin{array}{l}0,130 \\
(0,104)\end{array}$ & $\begin{array}{l}0,139 \\
(0,088)\end{array}$ & $\begin{array}{c}0,084 \\
(0,061)\end{array}$ & $\begin{array}{l}0,061 \\
(0,062)\end{array}$ & $\begin{array}{c}0,027 \\
(0,057)\end{array}$ & $\begin{array}{l}0,107^{*} \\
(0,055)\end{array}$ & $\begin{array}{l}0,016 \\
(0,046)\end{array}$ \\
\hline Sexo feminino & $\begin{array}{l}0,076 \\
(0,059)\end{array}$ & $\begin{array}{l}0,070 \\
(0,102)\end{array}$ & $\begin{array}{l}0,169^{*} \\
(0,088)\end{array}$ & $\begin{array}{l}0,112^{*} \\
(0,058)\end{array}$ & $\begin{array}{l}-0,009 \\
(0,059)\end{array}$ & $\begin{array}{l}-0,060 \\
(0,054)\end{array}$ & $\begin{array}{c}0,062 \\
(0,054)\end{array}$ & $\begin{array}{l}0,001 \\
(0,045)\end{array}$ \\
\hline $\begin{array}{l}\text { Escalão etário } \\
\text { [25-44] }\end{array}$ & $\begin{array}{l}0,211 \\
(0,133)\end{array}$ & $\begin{array}{l}-0,025 \\
(0,199)\end{array}$ & $\begin{array}{l}0,181 \\
(0,165)\end{array}$ & $\begin{array}{l}0,239^{* *} \\
(0,119)\end{array}$ & $\begin{array}{c}0,147 \\
(0,121)\end{array}$ & $\begin{array}{l}0,110 \\
(0,115)\end{array}$ & $\begin{array}{c}0,122 \\
(0,117)\end{array}$ & $\begin{array}{l}0,048 \\
(0,096)\end{array}$ \\
\hline $\begin{array}{l}\text { Escalão etário } \\
\text { [45-64] }\end{array}$ & $\begin{array}{l}0,166 \\
(0,130)\end{array}$ & $\begin{array}{l}-0,025 \\
(0,194)\end{array}$ & $\begin{array}{l}0,196 \\
(0,160)\end{array}$ & $\begin{array}{l}0,241^{* *} \\
(0,116)\end{array}$ & $\begin{array}{l}0,189 \\
(0,119)\end{array}$ & $\begin{array}{l}0,040 \\
(0,112)\end{array}$ & $\begin{array}{l}0,091 \\
(0,115)\end{array}$ & $\begin{array}{r}0,073 \\
(0,094)\end{array}$ \\
\hline Escalão etário & 0,224 & $-0,040$ & 0,148 & $0,362^{* * *}$ & $0,225^{*}$ & 0,015 & 0,124 & 0,154 \\
\hline$[65-\ldots]$ & $(0,140)$ & $(0,212)$ & $(0,174)$ & $(0,129)$ & $(0,134)$ & $(0,124)$ & $(0,125)$ & $(0,106)$ \\
\hline $\begin{array}{l}\text { Habilitações, } \\
\text { secundário }\end{array}$ & $\begin{array}{l}-0,102 \\
(0,0930)\end{array}$ & $\begin{array}{l}-0,105 \\
(0,166)\end{array}$ & $\begin{array}{l}-0,346^{* *} \\
(0,145)\end{array}$ & $\begin{array}{l}-0,044 \\
(0,099)\end{array}$ & $\begin{array}{l}-0,125 \\
(0,102)\end{array}$ & $\begin{array}{l}-0,173^{* *} \\
(0,088)\end{array}$ & $\begin{array}{l}-0,162^{*} \\
(0,085)\end{array}$ & $\begin{array}{l}-0,120 \\
(0,078)\end{array}$ \\
\hline $\begin{array}{l}\text { Habilitações, } \\
\text { superior }\end{array}$ & $\begin{array}{l}-0,147^{*} \\
(0,081)\end{array}$ & $\begin{array}{l}-0,114 \\
(0,152)\end{array}$ & $\begin{array}{l}-0,201 \\
(0,129)\end{array}$ & $\begin{array}{l}-0,008 \\
(0,089)\end{array}$ & $\begin{array}{l}-0,063 \\
(0,092)\end{array}$ & $\begin{array}{l}-0,127 \\
(0,078)\end{array}$ & $\begin{array}{l}-0,078 \\
(0,076)\end{array}$ & $\begin{array}{l}-0,017 \\
(0,071)\end{array}$ \\
\hline Observações & 266 & 102 & 122 & 283 & 285 & 337 & 321 & 505 \\
\hline
\end{tabular}


Os resultados obtidos permitem concluir que, no que diz respeito à probabilidade de os indivíduos avaliarem um item como muito bom, apenas se observam diferenças entre os visitantes nacionais e estrangeiros na avaliação dos locais escolhidos para a realização dos eventos, sendo os mesmos mais apreciados pelos visitantes estrangeiros. As mulheres, comparativamente com os homens, avaliam melhor a programação, que tende a ser mais valorizada à medida que a idade aumenta. Entre os indivíduos no escalão etário mais elevado, também se observa uma maior valorização da diversidade da programação. Finalmente, níveis de escolaridade mais elevados estão associados a indivíduos mais críticos, em particular os indivíduos com nível de escolaridade superior tendem a ser mais críticos relativamente às procissões e indivíduos com o ensino secundário tendem a ser mais críticos relativamente às exposições, divulgação e locais, comparativamente aos indivíduos com o ensino básico.

O grau de envolvimento dos habitantes da cidade, quer participando, quer assistindo aos eventos, motiva o interesse em aferir também o grau de satisfação dos residentes. Assim, reproduziu-se o exercício na base da Tabela 4, considerando para além dos visitantes e a sua origem, os residentes. Os resultados obtidos estão apresentados na Tabela 5.

\begin{tabular}{|c|c|c|c|c|c|c|c|c|}
\hline Variáveis & $\begin{array}{c}\text { Procissões } \\
\text { (1) }\end{array}$ & $\begin{array}{c}\text { Concertos } \\
\text { (2) }\end{array}$ & $\begin{array}{c}\text { Exposições } \\
\text { (3) }\end{array}$ & $\begin{array}{c}\text { Programa } \\
\text { (4) }\end{array}$ & $\begin{array}{c}\text { Diversidade } \\
\text { (5) }\end{array}$ & $\begin{array}{c}\text { Divulgação } \\
\text { (6) }\end{array}$ & $\begin{array}{l}\text { Locais } \\
\text { (7) }\end{array}$ & $\begin{array}{c}\text { Global } \\
(8)\end{array}$ \\
\hline $\begin{array}{l}\text { isitante } \\
\text { acional }\end{array}$ & $\begin{array}{l}-0,015 \\
(0,050)\end{array}$ & $\begin{array}{l}0,013 \\
(0,085)\end{array}$ & $\begin{array}{l}-0,034 \\
(0,077)\end{array}$ & $\begin{array}{l}-0,031 \\
(0,053)\end{array}$ & $\begin{array}{l}-0,040 \\
(0,053)\end{array}$ & $\begin{array}{l}-0,012 \\
(0,049)\end{array}$ & $\begin{array}{l}-0,054 \\
(0,049)\end{array}$ & $\begin{array}{l}-0,040 \\
(0,044)\end{array}$ \\
\hline $\begin{array}{l}\text { Visitante } \\
\text { estrangeiro }\end{array}$ & $\begin{array}{l}0,003 \\
(0,057)\end{array}$ & $\begin{array}{l}0,141 \\
(0,089)\end{array}$ & $\begin{array}{l}0,077 \\
(0,084)\end{array}$ & $\begin{array}{l}0,049 \\
(0,061)\end{array}$ & $\begin{array}{l}0,016 \\
(0,061)\end{array}$ & $\begin{array}{l}0,022 \\
(0,056)\end{array}$ & $\begin{array}{l}0,050 \\
(0,054)\end{array}$ & $\begin{array}{l}-0,013 \\
(0,046)\end{array}$ \\
\hline exo feminino & $\begin{array}{l}0,080^{*} \\
(0,044)\end{array}$ & $\begin{array}{l}0,058 \\
(0,072)\end{array}$ & $\begin{array}{c}0,104 \\
(0,066)\end{array}$ & $\begin{array}{l}0,090^{* *} \\
(0,046)\end{array}$ & $\begin{array}{l}0,036 \\
(0,046)\end{array}$ & $\begin{array}{l}0,029 \\
(0,043)\end{array}$ & $\begin{array}{c}0,068 \\
(0,042)\end{array}$ & $\begin{array}{c}0,030 \\
(0,036)\end{array}$ \\
\hline $\begin{array}{l}\text { scalão etário } \\
\text { 25-44] }\end{array}$ & $\begin{array}{l}0,247^{* *} \\
(0,096)\end{array}$ & 0,20 & 0,320 & $\begin{array}{l}0,294^{* * *} \\
(0,086)\end{array}$ & $(0,092)$ & $-0,010$ & 0,105 & $\begin{array}{l}0,150^{* *} \\
(0,072)\end{array}$ \\
\hline $\begin{array}{l}\text { scalão etáric } \\
45-64]\end{array}$ & $\begin{array}{l}0,231^{* *} \\
(0,095)\end{array}$ & $\begin{array}{l}0,187 \\
(0,133)\end{array}$ & $\begin{array}{l}0,263^{* *} \\
(0,114)\end{array}$ & $\begin{array}{c}0,299^{* * *} \\
(0,084)\end{array}$ & $\begin{array}{l}0,179^{* *} \\
(0,091)\end{array}$ & $\begin{array}{l}-0,050 \\
(0,087)\end{array}$ & $\begin{array}{l}0,103 \\
(0,089)\end{array}$ & $\begin{array}{l}0,163^{* *} \\
(0,071)\end{array}$ \\
\hline $\begin{array}{l}\text { scalão etá } \\
65-. . .]\end{array}$ & $0,222^{* *}$ & 0,185 & $309^{* *}$ & $0,352^{* * *}$ & $0,208^{* *}$ & $-0,093$ & 0,157 & $0,264^{* * *}$ \\
\hline $\begin{array}{l}\text { Habilitações, } \\
\text { secundário }\end{array}$ & $\begin{array}{c}-0,196^{* * *} \\
(0,063)\end{array}$ & $\begin{array}{l}-0,190^{*} \\
(0,107)\end{array}$ & $\begin{array}{l}-0,248^{* *} \\
(0,100)\end{array}$ & $\begin{array}{l}-0,072 \\
(0,073)\end{array}$ & $\begin{array}{l}-0,065 \\
(0,074)\end{array}$ & $\begin{array}{l}-0,131^{* *} \\
(0,066)\end{array}$ & $\begin{array}{l}-0,114^{*} \\
(0,066)\end{array}$ & $\begin{array}{l}-0,133^{* *} \\
(0,059)\end{array}$ \\
\hline $\begin{array}{l}\text { Habilitações, } \\
\text { superior }\end{array}$ & $\begin{array}{c}-0,216^{* * *} \\
(0,055)\end{array}$ & $\begin{array}{l}-0,173^{*} \\
(0,097)\end{array}$ & $\begin{array}{l}-0,130 \\
(0,092)\end{array}$ & $\begin{array}{l}-0,035 \\
(0,066)\end{array}$ & $\begin{array}{l}-0,030 \\
(0,067)\end{array}$ & $\begin{array}{l}-0,107^{*} \\
(0,060)\end{array}$ & $\begin{array}{l}-0,038 \\
(0,059)\end{array}$ & $\begin{array}{l}-0,067 \\
(0,055)\end{array}$ \\
\hline bservações & 473 & 195 & 221 & 465 & 474 & 553 & 524 & 762 \\
\hline
\end{tabular}

\section{Tabela 5}

Determinantes da satisfação da programação residentes e visitantes. Nota. Erros-padrão entre parêntesis. ${ }^{* * *} p$ $<0,01,{ }^{* *} p<0,05,{ }^{*} p$ $<0,1$. Categorias base: sexo masculino; escalão etário [16-24]; habilitações ensino básico. Variável dependente $=$ 0 para respostas iguais ou inferiores a bom; = 1 para respostas $=$ muito bom. 
Os resultados sugerem que a origem dos indivíduos ou o facto de serem residentes não são fatores determinantes das diferenças em termos de satisfação. Encontramos diferenças com base no género, na idade e no nível de escolaridade: as mulheres, comparativamente aos homens, avaliam melhor a programação; à medida que a idade aumenta, a programação e a diversidade tendem a ser mais valorizadas, acontecendo o mesmo em termos globais; embora escalões etários mais elevados avaliem melhor as procissões e as exposições, esta diferença tende a diminuir com o aumento da idade, no caso das procissões, apresentando uma evolução em forma de U, no caso das exposições; níveis de escolaridade mais elevados estão associados a indivíduos mais críticos, nomeadamente, os indivíduos com o ensino secundário apresentam uma maior exigência relativamente a todos os itens com exceção da programação e diversidade, exigência que aumenta nos indivíduos com o ensino superior, no caso das procissões e diminui no caso dos concertos e da divulgação.

Os resultados obtidos estão em linha com os reportados na literatura, na medida em que a avaliação por parte dos homens tende a ser mais exigente, assim como a avaliação por parte dos indivíduos com níveis de escolaridade mais elevados. A eventual distinção entre visitantes nacionais e estrangeiros não é captada pela sua origem, podendo decorrer das características individuais de cada um dos perfis dos visitantes. Atendendo aos perfis dos visitantes nacionais e estrangeiros e à relação entre as características individuais e o grau de satisfação, a expetativa é que o nível de exigência seja superior entre os visitantes estrangeiros, contrariando, neste caso particular, outros resultados presentes na literatura. Finalmente, a idade influencia a satisfação, sugerindo, em geral, uma relação positiva entre a idade e o grau de satisfação.

\section{Conclusões}

Observamos diferenças no perfil do visitante entre visitantes nacionais e estrangeiros. Especificamente, os visitantes do sexo masculino, mais velhos e com níveis de escolaridade mais elevados, têm maior probabilidade de ser estrangeiros. Sendo os visitantes estrangeiros os que efetuam uma despesa média mais elevada (Cerejeira et al., 2018) e, por isso, têm um impacto económico mais significativo na cidade e na região, as campanhas promocionais destinadas a atrair estes visitantes deverão ser adequadas a este perfil.

Relativamente à programação, verificamos que os visitantes estrangeiros tendem a manifestar preferência pela diversidade da programação, valorando menos a componente religiosa do evento. Uma escolha adequada dos locais escolhidos para a realização dos eventos também contribui de forma significativa para a sua satisfação.

Independentemente da origem geográfica (nacionais ou estrangeiros) dos visitantes e turistas, parece ser evidente que a satisfação com as procissões tende a diminuir com a idade e o nível de escolaridade. Esta evidência sugere a necessidade de adequar a programação de forma a satisfazer os diferentes públicos. 


\section{Referências}

Agyeiwaah, E., Adongo, R., Dimache, A., \& Wondirad, A. (2016). Make a customer, not a sale: Tourist satisfaction in Hong Kong. Tourism Management, 57, 68-79. https://doi.org/10.1016/j.tourman.2016.05.014

Alegre, J., \& Garau, J. (2010). Tourist satisfaction and dissatisfaction. Annals of Tourism Research, 37(1), 52-73. https://doi.org/10.1016/j.annals.2009.07.001

Andriotis, K., Agiomirgianakis, G., \& Mihiotis, A. (2008). Measuring tourist satisfaction - a factor-cluster segmentation approach. Journal of Vacation Marketing, 14, 221-235. https://doi. org/10.1177/1356766708090584

Barroso, N. (2018). O impacte económico do turismo religioso em Braga: 0 caso da Semana Santa [Dissertação de mestrado,Universidade do Minho]. RepositóriUM. http://hdl.handle.net/1822/59381

Cerejeira, J., Correia, I., \& Sousa, S. (2018). Avaliação do impacto económico da Semana Santa 2017. Comissão da Quaresma e Solenidades da Semana Santa de Braga.

Correia, A., Serra, J., \& Artal-Tur, A. (2017). Steady tourists' relationship with a mature destination: The case of Portugal. Tourism Economics, 23(4), 803-815. http://hdl.handle.net/10400.1/13109

Cracolici, M., \& Nijkamp, P. (2009). The attractiveness and competitiveness of tourist destinations: A study of Southern Italian regions. Tourism management, 30(3), 336-344. https://doi.org/10.1016/j.tourman.2008.07.006

Esu, B., \& Arrey, V. (2009). Tourists' satisfaction with cultural tourism festival: A case study of Calabar Carnival Festival, Nigeria. International Journal of Business and Management, 3(4), 116-125. https://doi. org/10.5539/ijbm.v4n3p116

Huh, J. (2002). Tourist satisfaction with cultural/heritage site: The Virginia Triangle [Dissertação de mestrado, Virginia Polytechnic Institute and State University]. VTechWorks. https://vtechworks.lib. vt.edu/handle/10919/32742

Kerstetter, D., Confer, J., \& Graefe, A. (2001). An exploration of the specialization concept within the context of heritage tourism. Journal of Travel Research, 39(3), 267-274. https://doi. org/10.1177/004728750103900304

Master, H., \& Prideaux, B. (2000). Culture and vacation satisfaction: A study of Taiwanese tourists in South East Queensland. Tourism Management, 21(5), 445-449. https://doi.org/10.1016/S02615177(99)00100-4

Mechinda, P., Serirat, S., \& Gulid, N. (2009). An examination of tourists' attitudinal and behavioral loyalty: Comparison between domestic and international tourists. Journal of Vacation Marketing, 15(2), 129-148. https://doi.org/10.1177/1356766708100820

Qu, H., \& Li, I. (1997). The characteristics and satisfaction of mainland Chinese visitors to Hong Kong. Journal of Travel Research, 35(4), 37-41. https://doi.org/10.1177/004728759703500406

Sánchez-Cañizares, S., \& López-Guzmán, T. (2012). Gastronomy as a tourism resource: Profile of the culinary tourist. Current Issues in Tourism, 15(3), 229-245. https://doi.org/10.1080/13683500.2011.589895

Santos, J. (2011). Os impactos do turismo religioso - 0 caso da Semana Santa em Braga. [Dissertação de mestrado, Universidade Fernando Pessoa]. Repositório Institucional da Universidade Fernando Pessoa. http://hdl.handle.net/10284/2237

Silva, M. (2015). 0 turismo religioso na Semana Santa em Braga [Dissertação de mestrado,Universidade do Minho]. RepositóriUM. http://hdl.handle.net/1822/40731

Valle, P., Silva, J., Mendes, J., \& Guerreiro, M. (2006). Tourist satisfaction and destination loyalty intention: A structural and categorical analysis. International Journal of Business Science and Applied Management, 1(1), 25-44. 